\title{
Thoracic Kyphosis Angle in Relation to Low Back Pain among Dentists in Iran
}

\author{
Hamed Nadri ${ }^{1}$, Bita Rohani ${ }^{2}$, Gholamheidar Teimori ${ }^{3,4}$, Shahram Vosoughi ${ }^{5}$, Fatemeh Fasih-Ramandi ${ }^{*}$ \\ ${ }^{1}$ Tarbiat Modares University, Tehran, Iran; ${ }^{2}$ School of Dentistry, Aja University of Medical Sciences, Tehran, Iran; \\ ${ }^{3}$ Department of Environmental Health, School of Health, Torbat Heydariyeh University of Medical Sciences; ${ }^{4}$ Health \\ Sciences Research Center, School of Health, Torbat Heydariyeh University of Medical Sciences, Torbat Heydariyeh, Iran; \\ ${ }^{5}$ School of Health, Iran University of Medical Sciences, Tehran, Iran; ${ }^{6}$ Student Research Committee, Shahid Beheshti \\ University of Medical Sciences, Tehran, Iran
}

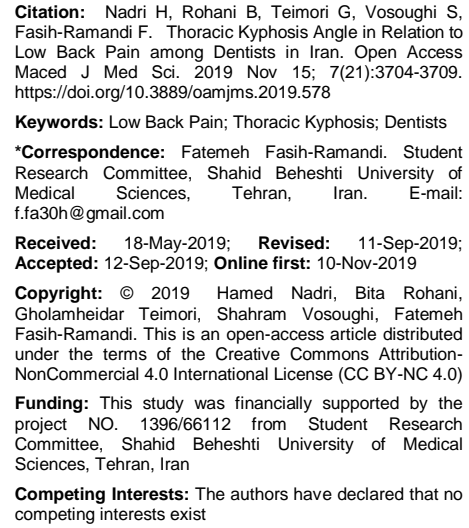

Abstract

BACKGROUND: Non-specific low back pain (LBP) has a direct impact on the quality of life, active days at work and health care costs.

AIM: This study was conducted to determine the relationship between LBP and thoracic kyphosis angle among dentists.

MATERIAL AND METHODS: This cross-sectional and descriptive-analytical study carried out in the form of census among 84 dentists employed in a specialised clinic in Iran. Dentists LBP prevalence and intensity and thoracic kyphosis angle were evaluated respectively with the self-administered body map questionnaire, visual analogue scale and flexicurve ruler. Statistical data analysis was done using SPSS software, version 22.

RESULTS: The data showed that the prevalence of LBP in dentists was $44.9 \%$ and intensity of LBP was reported about $71.9 \pm 19.34$. Pearson correlation coefficient between thoracic kyphosis angle and dentist's characteristics was not significant except for work experience. The single linear regression model showed that $1.3 \%$ of thoracic kyphosis angle changes was positively dependent on LBP. Also, the present study proved that thoracic kyphosis angle changes were positively dependent to $2.6 \%, 10.8 \%$ and 5.7 percent of age, work experience and Body Mass Index (BMI), respectively.

CONCLUSION: Despite the lack of significant statistical relation between LBP and thoracic kyphosis angle, there is a high prevalence and intensity of LBP among Dentists. To reduce the risk of work-related LBP among dentists, managing factors such as BMI, work postures and exercises during work should be taken into consideration.

\section{Introduction}

Musculoskeletal disorders are the most common and most costly occupational injuries; because one-third of work-related injuries in each year and approximately half of all work-related illnesses account for musculoskeletal disorders as these disorders are considered being the hidden epidemic in the today world [1]. It is estimated that the direct and indirect costs of musculoskeletal disorders account for about of $1 \%$ the gross national product (GDP) of industrial countries [2], and are considered as the main causes of lost working time, increasing costs, and workforce damages [3], [4]. As well as, these disorders are one of the main causes of absenteeism in the workplace, so that according to previous studies, about of $40 \%$ of the compensation paid to workers was related to musculoskeletal disorders [5], [6].

Musculoskeletal disorders are prevalent among different occupations, and dentists are not excluded from this norm. In the dental profession, due to repetitive movements, long-term work in static situations, awkward postures, use of excessive force and inappropriate working tools, there is the probability of musculoskeletal discomfort in the form of pain in various areas of the body. So that, Shrestha et al., reported the highest prevalence of 
musculoskeletal disorders among dentists in the lumbar (80\%), neck (58.8\%) and shoulder (47\%) [7], and also according to Tim and colleagues study, the highest prevalence of these disorders was reported in the neck and shoulder with range of 37 to $72 \%$ and 11 to $35 \%$, respectively [8]. Based on studies, more than $90 \%$ of dentists postures during work have moderate and high-risk levels, as they have the worst postures while performing some of their tasks, such as surgery, endometrium, etc., which require corrective actions [9], [10].

Thoracic kyphosis is the main curvature of the vertebral column, which consists of twelve vertebrae [11]. The increase in this curvature (arch) is due to changes in the intervertebral disc and height of the vertebra by reducing the anterior height of the vertebral body and the imbalance between the soft tissues and the anterior and posterior supporting muscles. Thoracic kyphosis is the increase of the thoracic spine curvature in the sagittal plane. Psychological agents such as sadness, depression, weakness and excitement can increase the kyphosis arch [12], [13]. Based on biomechanical information, thoracic kyphosis may be associated with increased pressure on muscles and muscle strength and accelerates the degeneration process, dysfunction, and pain [14]. Increased thoracic kyphosis is associated with decreased body function [15] impaired pulmonary function [16], and increased neck pain, headache and subacromial impingement pain syndrome [17], [18]. This abnormality is most commonly seen in women, for reasons such as muscle weakness, increased fat percentage, and repetition of false habits [19], [20]. Accurate, early and timely identification of these abnormalities can be effective in preventing and correcting them. Various instruments have been used to evaluation and diagnosis of these abnormalities, which include the spinal mouse, pantograph spinal, inclinometer, flexible ruler and kyphometer [21]. The standard method for measuring the thoracic kyphosis is Cobb's radiographic method, but because of exposure to radiation and costly, this method is not appropriate [22], [23]. Therefore, in this study, a flexible ruler was used to evaluate the thoracic kyphosis. The validity of the flexible ruler in measuring thoracic kyphosis has been proven in many studies abroad and inside our country [24], [25]. Considering the importance of prevention and treatment of musculoskeletal disorders among dentists, this study aimed to measure the thoracic kyphosis and its association with low back pain (LBP) intensity.

\section{Methods}

This cross-sectional study was conducted among all 84 dentists employed in a specialized dental clinic in Tehran, Iran, in 2018. The criteria for inclusion in the study were the lack of a history of spinal surgery and traumatic orthopaedic problems such as acute back and nerve problems, inflammatory diseases such as Ankylosing spondylitis involving the spine, congenital diseases such as scoliosis and hemivertebrae. Due to the inclusion criteria, 6 dentists were excluded from the study. In the first phase of this study, the prevalence and intensity of dentists LBP were evaluated with the self-administered body map questionnaire along with a visual analogue discomfort scale. In the second phase, the thoracic kyphosis angle was measured using the flexicurve ruler in dentists with LBP. All participants agreed to participate in this study, read and signed an informed consent form.

\section{Body Map Questionnaire}

To evaluate the prevalence of LBP, body map questionnaire was used [26]. In this questionnaire to facilitate understanding and position musculoskeletal disorders, the body was divided into 13 areas, including low back in the form of a map.

\section{Visual Analog Discomfort Scale}

To indicate the level of discomfort, the subjects were asked to mark the degree of subjective of LBP on a horizontal line of $100 \mathrm{~mm}$ long. The intensity of LBP was recorded numerically from zero (without discomfort) to 100 (severe discomfort) using a millimetre ruler. LBP intensity divided into mild (0$20)$, moderate (21-40), severe (41-60), disabling (61$80)$ and severe disabling (81-100).

\section{Thoracic Kyphosis Angle Measurement}

Thoracic kyphosis angle was measured in each subject using a flexicurve ruler (Ghamat Pooyan Co., Iran) based on Hoppenfeld's method, according to the distance of the spinous process of two reference bones, i.e. C7 and T12. The Hoppenfeld method was employed to find the two bone landmarks [27]. Finally, the angle between these two bone landmarks (C7 and T12) was calculated and reported as the thoracic kyphosis angle. Besides, the sensitivity and specificity of the flexicurve method for diagnosing hyper thoracic kyphosis were $85 \%$ and $97 \%$ respectively [28]. Also, the ICC of the flexicurve method obtained by Iranian studies, Khalkhali et al., [29] and Kargarfard et al., [30] was 0.97 and 0.99, respectively.

Statistical data analysis was done using SPSS (version 22.0, IBM Corporation, Armonk, NY, USA). Kolmogorov-Smirnov test was used to determine the normality of the data. Besides, we used the t-test, Mann-Whitney, Spearman correlation 
coefficient, single and multiple linear regressions.

\section{Results}

In this study, a total of 84 dentists participating in this study, six dentists were excluded due to lack of inclusion criteria, and 78 dentists were examined. $55.1 \%$ of participants were male and $44.9 \%$ female. $24.4 \%$ of them were single and $75.6 \%$ married.

The mean age, work experience, weight, height, and body mass index (BMI) of dentists were equal to $38.47 \pm 6.54$ years, $13.29 \pm 7.24$ years, 75.12 $\pm 17.66 \mathrm{~kg}, 26172.41 \pm 9.9 \mathrm{~cm}$ and $24.98 \pm 4.16$ $\mathrm{kg} / \mathrm{m}^{2}$, respectively. Furthermore, demographic variables distribution of the studied dentists was reported in Table 1. There was no significant difference between demographic variables in two groups with and without $\operatorname{LBP}(P>0.05)$.

Table 1: Distribution of dentist's demographic characteristics $(n=78)$

\begin{tabular}{|c|c|c|c|}
\hline \multirow{2}{*}{ Variable } & \multicolumn{2}{|c|}{ Low Back Pain } & \multirow{2}{*}{$P$-value } \\
\hline & Yes & No & \\
\hline$\overline{\text { Age (years) }}$ & $38.7 \pm 6.6$ & $38.3 \pm 6.5$ & 0.772 \\
\hline Work experience (years) & $13.9 \pm 7.2$ & $12.8 \pm 7.3$ & 0.471 \\
\hline Weight $(\mathrm{kg})$ & $78.4 \pm 18.4$ & $72.4 \pm 16.7$ & 0.136 \\
\hline Height $(\mathrm{cm})$ & $173.2 \pm 9.5$ & $171.7 \pm 9.1$ & 0.455 \\
\hline $\mathrm{BMI}\left(\mathrm{kg} / \mathrm{m}^{2}\right)$ & $25.8 \pm 4.3$ & $24.3 \pm 3.9$ & 0.104 \\
\hline
\end{tabular}

The prevalence of LBP in dentists was reported at $44.9 \%$. The mean of LBP intensity in dentists was $71.9 \pm 19.34$. The results of the classification of the LBP intensity obtained from the visual analogue discomfort scale (Table 2) showed that the highest relative frequency among the subjects was related to disabling pain and severe pain, with $34.3 \%$ and $31.4 \%$, respectively. The relationship between LBP intensity and angle of thoracic kyphosis was investigated among dentists with LBP by gender and marital status. The results of the Mann-Whitney $U$ test indicated that there was no significant correlation between LBP intensity, gender, and marital status among dentists $(P>0.05)$. Also, independent sample t-test did not show a significant relationship between the mean angle of thoracic kyphosis and gender and marital status of the dentists $(P>0.05)$.

Table 2: Percent distribution of low back pain among dentists using the visual analogue scale $(n=35)$

\begin{tabular}{lcccc}
\hline Low back pain (\%) & & & & \\
\hline Mild & Moderate & Severe & disabling & Severe disabling \\
0 & 5.7 & 31.4 & 34.3 & 28.6 \\
\hline
\end{tabular}

Table 3 illustrated the relationship between factors affecting on LBP in dentists using a single logistic regression. There was no significant correlation between LBP and demographic variables $(P>0.05)$. However, men had more the risk of LBP than women did. Likewise, the risk of LBP was higher in married than single. Dentists with high age or experience over 10 years had more LBP than others. The odds ratio of LBP was lower in dentists with exercise activity. With the increase in BMI, the odds ratio of LBP was increased. People with more daily work hours had a higher chance of LBP.

Table 3: Odds ratio and Cls for predictive factors of Low Back Pain in dentists $(n=78)$

\begin{tabular}{|c|c|c|c|c|c|c|}
\hline Variable & & $\begin{array}{l}\text { Frequency }(\%) \\
\text { of the total } \\
\text { sample }\end{array}$ & $\begin{array}{l}\text { Frequency (\%) } \\
\text { affected by LBP }\end{array}$ & $\begin{array}{l}\text { Odds } \\
\text { Ratio }\end{array}$ & $\begin{array}{l}\text { 95\% Confidence } \\
\text { intervals }\end{array}$ & $\begin{array}{c}\mathrm{P} \text { - } \\
\text { value }\end{array}$ \\
\hline \multirow{2}{*}{ Gender } & Female & $35(44.9)$ & $14(40)$ & 1 & Reference & \\
\hline & & $43(55.1)$ & & 1.432 & $0.581-3$ & 0.436 \\
\hline Marital & Single & 19 (24.4) & $8(22.9)$ & 1 & Reference & \\
\hline Status & $\begin{array}{l}\text { Married } \\
<40\end{array}$ & 59 & $\begin{array}{l}27(77.1) \\
24(68.6)\end{array}$ & 1.160 & $\begin{array}{l}0.408- \\
\text { Refer }\end{array}$ & 0.781 \\
\hline \multirow[t]{2}{*}{ Age (years) } & $40-50$ & $22(28.2)$ & $10(28.6)$ & 1.655 & $0.141-19.386$ & 0.688 \\
\hline & & & & 1.667 & 0.131 & 0.694 \\
\hline Work & $<1$ & $27(34.6)$ & 9( & 1 & Reference & \\
\hline \multirow{2}{*}{$\begin{array}{l}\text { (years) } \\
\text { (a)e }\end{array}$} & 10 & $\begin{array}{l}35(44.9) \\
16(20.5)\end{array}$ & $\begin{array}{l}18(51.4) \\
8(22.9)\end{array}$ & $\begin{array}{l}2.118 \\
2.00\end{array}$ & $\begin{array}{l}0.749-5.986 \\
0.564-7.087\end{array}$ & $\begin{array}{l}0.157 \\
0.283\end{array}$ \\
\hline & $\begin{array}{l}>20 \\
<18.5\end{array}$ & $\begin{array}{c}16(20.5) \\
5(6.4)\end{array}$ & $\begin{array}{l}8(22.9) \\
2(5.7)\end{array}$ & $\begin{array}{c}2.00 \\
1\end{array}$ & $\begin{array}{c}0.564-1.087 \\
\text { Reference }\end{array}$ & \\
\hline \multirow{3}{*}{ BMI $\left(\mathrm{kg} / \mathrm{m}^{2}\right)$} & $18.5-25$ & $30(38.5)$ & $11(31.4)$ & 0.868 & $0.125-6.026$ & 0.886 \\
\hline & & & & 1.342 & & 0.762 \\
\hline & $>30$ & 7 & & 3.750 & $0.331-42.467$ & 0.286 \\
\hline arcise & No & $30(38.5)$ & $15(4$ & 1 & Reference & \\
\hline & Yes & 48 & 20 & 0.714 & 0.28 & 0.472 \\
\hline & Le & $12(15.4)$ & 6 (17.1) & 1 & Reference & \\
\hline w & & $66(84.6)$ & $29(8$ & 0.784 & $0.229-2.686$ & 0.698 \\
\hline Daily & $<8$ hours & $21(26.9)$ & $8(22.9)$ & 1 & Reference & \\
\hline hours & $\geq 8$ ho & $57(73.1)$ & $27(77.1)$ & 1.462 & $0.526-4.067$ & 0.466 \\
\hline Weekly & $<40$ hours & $23(29.5)$ & $10(28.6)$ & 1 & Reference & \\
\hline work hours & $\geq 40$ hours & $55(70.5)$ & $25(71.4)$ & 1.083 & $0.406-2.888$ & 0.873 \\
\hline
\end{tabular}

Correlation between age, work experience and BMI of dentists was surveyed with the angle of thoracic kyphosis using the Pearson statistical test (Table 4), and the results showed that there is a significant relationship between work experience and thoracic kyphosis $(P=0.045)$.

Table 4: Correlation between Thoracic Kyphosis and dentist's characteristics $(n=35)$

\begin{tabular}{lcccccc}
\hline \multirow{2}{*}{ Variable } & \multicolumn{2}{c}{ Age } & \multicolumn{2}{c}{ Work experience } & \multicolumn{2}{c}{ BMl } \\
\cline { 2 - 7 } & $p$-value & $r$ & $p$-value & $r$ & $p$-value & $r$ \\
\hline $\begin{array}{l}\text { Thoracic } \\
\text { Kyphosis }\end{array}$ & 0.101 & 0.282 & 0.045 & 0.340 & 0.170 & 0.237 \\
\hline *Pearson correlation test. & & & & & &
\end{tabular}

Regression models of the correlation between LBP and thoracic kyphosis exhibited in Table 5. Based on the linear regression equation, $1.3 \%$ of changes in thoracic kyphosis are dependent on the LBP. The correlation between LBP and thoracic kyphosis is a positive relationship, and somewhat LBP increases the thoracic kyphosis. Based on the multiple regression equation, $2.6 \%, 10.8 \%$, and 5.7 percent of the thoracic kyphosis changes are positively correlated with age, work experience, and BMI, respectively, and 36.6 percent of changes in thoracic kyphosis is negatively related to gender.

Table 5: Linear regression models for correlates of low back pain and Thoracic Kyphosis

\begin{tabular}{lccc}
\hline Variable & Adjusted $\mathrm{R}^{2}$ & $\mathrm{P}$-value & Linear Regression Equation \\
\hline LBP & 0.686 & $0.702^{\mathrm{a}}$ & $\begin{array}{c}\text { Thoracic Kyphosis }=38.293+(0.013 \times \text { LBP }) \\
\text { Thoracic Kyphosis }=38.293+(0.006 \times \text { LBP })\end{array}$ \\
$\begin{array}{l}\text { LBP with age \& } \\
\text { work experience \& } \\
\text { BMl \& gender }\end{array}$ & 0.008 & $0.405^{\mathrm{b}}$ & $\begin{array}{c}0.026 \times \text { age })+(0.108 \times \text { work experience })+ \\
(0.057 \times \mathrm{BMI})-(0.366 \times \text { gender })\end{array}$ \\
$\begin{array}{l}\text { a } \text { Single linear regression; }{ }^{\mathrm{b}} \text { Multiple linear regression. }\end{array}$
\end{tabular}




\section{Discussion}

The results of this study showed that dentists have a high LBP prevalence and pain intensity so that these results are consistent with the LBP prevalence results of similar studies among dentists, including Nadri et al., (LBP 34.5\%) [31], Varmazyar et al., (LBP 42.9\%) [32], Motemayel Ahmadi et al., (LBP 16.9\%) [33], Askaripoor et al., (LBP 46\%) [9], Pourabas et al., (LBP 22.9\%) [34], Vakili et al., (40.6\%) [35], Samat et al., (LBP 44.9\%) [36] and Gaowgzeh et al., (LBP 70\%) [37].

Investigating the factors affecting on LBP in dentists using single logistic regression showed that despite the lack of significant correlation between LBP and demographic variables; odds ratio of LBP in men were more than women and as well as married than single. Furthermore, with increasing the age and/or work experience (over 10 years), daily working hours, increase BMI and lack of exercise activity, the odds ratio of LBP has increased in dentists.

The result of this study is consistent with the result of Nadri et al., [31]. In a study by MohseniBandpei et al., the higher LBP was reported among people with the work experience more than 20 years [38]. Also, Aasa et al., reported the higher prevalence of LBP in men than women [39], while Leijon and Mulder reported a higher prevalence of LBP in women than men [40].

Assessing the discomfort along with the LBP prevalence, is a useful tool to determine the effectiveness of ergonomic interventions before and after study. The mean LBP intensity was $70.5 \pm 24$, which was consistent with the previous results by the researcher [31], [41]. In the Nield-Gehrig study, more than $80 \%$ of dentists complained of upper trunk and back pain, which was a direct consequence of posture and movements of dentists in daily work [42]. As well as, in Gaowgzeh et al., $90.5 \%$ of dentists had mild-tomoderate LBP intensity, and $9.5 \%$ had severe LBP intensity [37].

In the sitting position (on the seat during work), the low back arch decreased, and it can prevent from LBP [43]. Dentists should change their working positions based on the muscles group involved during different activities [44]. So that changing sitting and standing situations can be an effective strategy. Dentists, who are working only in sitting position, experienced more LBP (due to static posture) than those with standing and sitting rotation position [45].

Based on the results of the Pearson test, thoracic kyphosis presented a significant correlation with work experience. Despite the lack of significant correlation between thoracic kyphosis with LBP and demographic variables in both single and multiple linear regressions, according to the results of single linear regression, $1.3 \%$ of changes in thoracic kyphosis were related to LBP. In multiple linear regression, changes in thoracic kyphosis have increased with increase work experience and BMI, and thoracic kyphosis in women has been higher. However, in multiple linear regressions, changes in thoracic kyphosis are not approximately related to the LBP.

Previous studies have revealed that gender is a risk factor for the intensity of LBP and thoracic kyphosis [46]. In the study of Kargarfard et al., the average degree of thoracic kyphosis was higher in boys than girls, and there was a significant difference [30]. The difference in reporting the results may be due to the demographic characteristics of individuals or studied population.

According to the results of previous studies, the use of preventive strategies such as proper desk, regular and tensile exercises, use of the helpful instruments, use of the assistant, suitable posture can be associated with a reduction in LBP intensity as well as thoracic kyphosis [38]. In Kazemi et al., study, the reason of the reduction of thoracic kyphosis angle in the subjects after a period of exercise with the physioball can be attributed to strengthen the muscles of the posterior region of the spine (spinal extensor muscles) through strength and endurance exercises; as well as flexural exercises in the thoracic area [47]. Hrysomallis and Goodman [48] and Choi et al., [49] showed that the thoracic kyphosis is reduced by increasing the strength of the back extensor muscles through exercise. There also is a negative correlation between the back extensor muscles strength and thoracic kyphosis [50], [51]. The positive effects of physical activity with Physioball on the physiological and physical factors are well known.

Moreover, exercise with physio ball is a reliable way to achieve relaxation and happiness. So ergonomic training courses, back support programs, and exercise programs before and during work recommended to strengthen the musculoskeletal system and improve the musculoskeletal disorders in the work environment of dentists. It can be noted that the being cross-sectional and small sample size are the limitations of this study.

In conclusion, despite the lack of significant statistical relation between LBP and thoracic kyphosis angle, there is a high prevalence and intensity of LBP among Dentists. To reduce the risk of work-related LBP among dentists, managing factors related to LBP such as BMI, work postures and relaxation and stretching exercises during dentists' work should be taken into consideration. In addition to the above measures, effective training and ergonomic interventions to correct inappropriate work, postures can play an important role in preventing and managing MSDs. Additional research is required to determine the thoracic kyphosis angle about LBP in dentists. 


\section{Acknowledgement}

The authors appreciate the "student research committee" and "research and technology chancellor" at Shahid Beheshti University of Medical Sciences for their financial support of this study.

\section{References}

1. Tayyari F, Smith JL. Occupational ergonomics: principles and applications. Chapman \& Hall; 1997.

2. Yu W, Ignatius T, Wang X, Li Z, Wan S, Qiu H, et al. Effectiveness of participatory training for prevention of musculoskeletal disorders: a randomized controlled trial. International archives of occupational and environmental health. 2013; 86(4):431-40. https://doi.org/10.1007/s00420-012-0775-3 PMid:22544420

3. McAtamney L, Corlett EN. RULA: a survey method for the investigation of work-related upper limb disorders. Applied ergonomics. 1993; 24(2):91-9. https://doi.org/10.1016/0003 6870(93) $90080-S$

4. Kemmlert K. Labor inspectorate investigation for the prevention of occupational musculo-skeletal injuries. licentiate thesis, National Institute of Occupational Health. 1994.

5. Hagberg M, Morgenstern $\mathrm{H}$, Kelsh M. Impact of occupations and job tasks on the prevalence of carpal tunnel syndrome.

Scandinavian Journal of work, Environment \& health. 1992:337-45. https://doi.org/10.5271/sjweh.1564 PMid:1485158

6. Takala J. Introductory report: decent work-safe work. InXVIth World Congress on Safety and Health at Work 2002 May 27. Austria Vienna.

7. Shrestha BP, Singh G, Niraula S. Work related complaints among dentists. Journal of Nepal Medical Association. 2008; 47(170):77-81. https://doi.org/10.31729/jnma.317

8. Morse $T$, Bruneau $H$, Michalak-Turcotte $C$, Sanders M, Warren $\mathrm{N}$, Dussetschleger $\mathrm{J}$, et al. Musculoskeletal disorders of the neck and shoulder in dental hygienists and dental hygiene students. American Dental Hygienists Association. 2007; 81(1):1-16.

9. Askaripoor T, Kermani A, Jandaghi J, Farivar F. Survey of Musculoskeletal Disorders and Ergonomic Risk Factors among Dentists and Providing Control Measures in Semnan. Health and Hygiene. 2013; 4(3).

10. Yaghobee S, Esmaeili V. Evaluation of the effect of the ergonomic principles' instructions on the dental students' postures an ergonomic assessment. Journal of Dental Medicine. 2010; 23(2):121-7.

11. Ryan SD, Fried LP. The impact of kyphosis on daily functioning. Journal of the American Geriatrics Society. 1997; 45(12):1479-86. https://doi.org/10.1111/j.15325415.1997.tb03199.x PMid:9400558

12. Bonney R, Corlett E. Head posture and loading of the cervical spine. Applied ergonomics. 2002; 33(5):415-7. https://doi.org/10.1016/S0003-6870(02)00036-4

13. Lintner D, Noonan TJ, Kibler WB. Injury patterns and biomechanics of the athlete's shoulder. Clinics in sports medicine. 2008; 27(4):527-51. https://doi.org/10.1016/j.csm.2008.07.007 PMid:19064144

14. Di Bari M, Chiarlone M, Matteuzzi D, Zacchei S, Pozzi C, Bellia $\mathrm{V}$, et al. Thoracic kyphosis and ventilatory dysfunction in unselected older persons: an epidemiological study in Dicomano, Italy. Journal of the American Geriatrics Society. 2004; 52(6):90915. https://doi.org/10.1111/j.1532-5415.2004.52257.x
PMid:15161454

15. Rajabi R, Doherty P, Goodarzi M, Hemayattalab R. Comparison of thoracic kyphosis in two groups of elite GrecoRoman and freestyle wrestlers and a group of non-athletic participants. British Journal of Sports Medicine. 2008; 42(3):229 32. https://doi.org/10.1136/bjsm.2006.033639 PMid:17615172

16. Feldenkrais M. Body and mature behaviour: A study of anxiety, sex, gravitation and learning. New York: International University Press Incorporated; 1994.

17. Finley MA, Lee RY. Effect of sitting posture on 3-dimensional scapular kinematics measured by skin-mounted electromagnetic tracking sensors. Archives of physical medicine and rehabilitation. 2003; 84(4):563-8. https://doi.org/10.1053/apmr.2003.50087 PMid:12690596

18. Gray J, Grimsby O. Interrelationship of the spine, rib cage, and shoulder. Physical Therapy of the Shoulder. Churchill Livingston, 2004. https://doi.org/10.1016/B978-044306614-6.50007-7 PMid:15019472

19. Ludewig PM, Cook TM. Alterations in shoulder kinematics and associated muscle activity in people with symptoms of shoulder impingement. Physical therapy. 2000; 80(3):276-91.

20. Daneshmandi H, Alizadeh M, Gharakhanlou R. Corrective exercises. Tehran: Samt Pub; 2008.

21. Rajabi R, Samadi H. Laboratory manual of predictors of sport injuries among junior soccer corrective exercise for post graduated students. Tehran: Tehran University Pub; 2008.

22. JR. C. Outline for the study of scoliosis. American Academy of Orthopaedic Surgeons Instr Course Lect. 1948; 5:261-75.

23. Briggs A, Wrigley T, Tully E, Adams P, Greig A, Bennell K. Radiographic measures of thoracic kyphosis in osteoporosis: Cobb and vertebral centroid angles. Skeletal radiology. 2007; 36(8):7617. https://doi.org/10.1007/s00256-007-0284-8 PMid:17437103

24. Hart DL, Rose SJ. Reliability of a noninvasive method for measuring the lumbar curve. Journal of Orthopaedic \& Sports Physical Therapy. 1986; 8(4):180-4. https://doi.org/10.2519/jospt.1986.8.4.180 PMid:18802227

25. Azadinia F, Kamyab M, Behtash H, Ganjavian M, MirzazadehJavaheri $M$. The validity and reliability of flexicurve for measuring kyphosis. Journal of Research in Rehabilitation Sciences. 2012; 8(4):1-10.

26. Karwowski W, Marras W. Body Discomfort Assessment Tools. The occupational ergonomics handbook In: Occupational ergonomics: engineering and administrative controls. New York: CRC PRES, 2005:1-26.

27. Hoppenfeld S. Physical Examination Of The Spine \& Extremities; chapter 9: Physical Examination of the Lumbar Spine. New York, 1976

28. Teixeira F, Carvalho G. Reliability and validity of thoracic kyphosis measurements using flexicurve method. Brazilian Journal of Physical Therapy. 2007; 11(3):199-204.

29. Khalkhali M, Parnianpor M, Karimi H, Mobini B, Kazemnezhad A. Investigation of validity and reproducibility of thoraces kyphose in postural hyperkyphosis by using flexicurve. Journal of Rehabilitation. 2003; 14:52-61.

30. Kargarfard M, Mahdavi-Nejad R, Ghasemi G, Rouzbehani R, Ghias M, Mahdavi-Jafari Z, et al. Assessment of Spinal Curvature in Isfahan University Students. Journal of Isfahan Medical School. 2010; 27(102):762-76.

31. Jackson RP, McManus AC. Radiographic Analysis of Sagittal Plane Alignment and Balance in Standing Volunteers and Patients with Low Back Pain Matched for Age, Sex, and Size: A Prospective Controlled Clinical Study. Spine. 1994; 19(14):1611-8.

https://doi.org/10.1097/00007632-199407001-00010 PMid:7939998

32. Nadri H, Nadri A, Rohani B, Fasih Ramandi F, Amin Sobhani M, Naseh I. Assessment of Musculoskeletal Disorders Prevalence and Body Discomfort among Dentists by Visual Analog Discomfort Scale. Journal of Mashhad Dental School. 2015; 39(4):363-72. 
33. Varmazyar S, Amini M, Kiafar S. Ergonomic Evaluation of Work Conditions in Qazvin Dentists and its Association with Musculoskeletal Disorders Using REBA Method. Journal of Islamic Dental Association of IRAN (JIDAI). 2012; 24(3):3.

34. Motemayel Ahmadi F, Abdolsamadi H, Roshanaei G, Jalilian S. Prevalence of Musculoskeletal Disorders among Hamadan General Dental Practitioners. Sci J Hamadan Univ Med Sci. 2012; 19(3):61-6.

35. Pourabas R, Shakoori K, Haji Dyzaji R. Evaluation of musculoskeletal pain and its risk factors among Tabriz dentists. Journal of Tabrize University of Medical Science. 2004; 38(64):349.

36. Vakili L, Halabchi F, Mansournia MA, Khami MR, Irandoost S, Alizadeh Z. Prevalence of common postural disorders among academic dental staff. Asian journal of sports medicine. 2016; 7(2). https://doi.org/10.5812/asjsm.29631 PMid:27625751 PMCid:PMC5003311

37. Samat RA, Shafei MN, Yaacob NA, Yusoff A. Prevalence and associated factors of back pain among dental personnel in northeastern state of malaysia. International Journal of Collaborative Research on internal medicine \& public health. 2011; 3(7):576-86.

38. Gaowgzeh RA, Chevidikunnan MF, Al Saif A, El-Gendy S, Karrouf G, Al Senany S. Prevalence of and risk factors for low back pain among dentists. Journal of physical therapy science. 2015; 27(9):2803. https://doi.org/10.1589/ipts.27.2803 PMid:26504297 PMCid:PMC4616098

39. Mohseni-Bandpei M, Rahmani N, Halimi F, Farooq M. The prevalence of low back pain in Iranian dentists: An epidemiological study. Pakistan journal of medical sciences. 2017; 33(2):280. https://doi.org/10.12669/pims.332.11519 PMid:28523022 PMCid:PMC5432689

40. Aasa U, Barnekow-Bergkvist M, Ängquist K-A, Brulin C. Relationships between work-related factors and disorders in the neck-shoulder and low-back region among female and male ambulance personnel. Journal of occupational health. 2005; 47(6):481-9. https://doi.org/10.1539/joh.47.481 PMid:16369110

41. Leijon O, Mulder M. Prevalence of low back pain and concurrent psychological distress over a 16-year period. Occupational and Environmental Medicine. 2009;66(2):137-9. https://doi.org/10.1136/oem.2008.040337 PMid:19028803

42. Nadri H, Fasih Ramandi F. Low back and neck pain intensity and relationship with disability index among dentists. JOHE. 2017; 5(4):218-25. https://doi.org/10.18869/acadpub.johe.5.4.218
43. Nield-Gehrig JS. Fundamentals of periodontal instrumentation \& advanced root instrumentation: Lippincott Williams \& Wilkins 2008.

44. Harrison DD, Harrison SO, Croft AC, Harrison DE, Troyanovich SJ. Sitting biomechanics part I: review of the literature. Journal of manipulative and physiological therapeutics. 1999; 22(9):594-609. https://doi.org/10.1016/S0161-4754(99)70020-5

45. Callaghan JP, McGILL SM. Low back joint loading and kinematics during standing and unsupported sitting. Ergonomics. 2001; 44(3):280-94. https://doi.org/10.1080/00140130118276 PMid: 11219760

46. Ratzon NZ, Yaros T, Mizlik A, Kanner T. Musculoskeletal symptoms among dentists in relation to work posture. Work. 2000; 15(3):153-8.

47. Morken T, Moen B, Riise T, Bergum O, Bua L, Vigeland Hauge $\mathrm{S}$, et al. Prevalence of musculoskeletal symptoms among aluminium workers. Occupational medicine. 2000; 50(6):414-21. https://doi.org/10.1093/occmed/50.6.414 PMid:10994244

48. Kazemi A, Mahdavinejad R, Ghasemi G, Sadeghi M. Effects of an 8-week exercise with Physioball on the correction of thoracic kyphosis, balance and quality of life in addicted men after quitting drugs. J Res Rehabil Sci. 2013; 9(2):328-37.

49. Hrysomallis C, Goodman C. A review of resistance exercise and posture realignment. The Journal of Strength \& Conditioning Research. 2001; 15(3):385-90. https://doi.org/10.1519/00124278200108000-00022 PMid:11710670

50. Choi E, Hur J, Yang J, Park D. The effect of thoracic exercise program on thoracic pain, kyphosis, and spinal mobility. Archives of Physical Medicine and Rehabilitation. 2005; 86(9):23-7. https://doi.org/10.1016/i.apmr.2005.07.123

51. Sinaki M, Brey RH, Hughes CA, Larson DR, Kaufman KR. Balance disorder and increased risk of falls in osteoporosis and kyphosis: significance of kyphotic posture and muscle strength. Osteoporosis international. 2005; 16(8):1004-10. https://doi.org/10.1007/s00198-004-1791-2 PMid:15549266

52. Arshadi R. Investigation of relation between erectorspine strength and spinal column felexibility with kyphose and lordose [MSC thesis]. Tehran, Iran: University of Tehran. 2007. 